Text S1. Consultation document for the 1st series of workshops

The following document was provided to the participants of the $1^{\text {st }}$ series of workshops one week prior to the event. 


\section{Forest carbon and climate change}

Climate change represents one of the most important environmental threats of the 21st century. It is caused by a global increase in greenhouse gases (GHGs) in the atmosphere, mainly due to use of fossil fuels and cement production. Land-use change, for example removing forest and using the land for agriculture or urban development (also known as deforestation), has a lesser but nevertheless important role.

We can reduce future changes in atmospheric GHG concentrations through strategies that reduce GHG emissions or increase GHG removals from the atmosphere. Activities that reduce emissions or increase removals compared to business-as-usual or "baseline" levels are considered climate change mitigation actions. The management of forests and the use of wood can make an important contribution to mitigation.

The term greenhouse gas (GHG) refers to any gas that absorbs infrared radiation and traps heat in the atmosphere. Many GHGs occur naturally, but human activity can causes emissions that increase the amount in the atmosphere. Carbon dioxide $\left(\mathrm{CO}_{2}\right)$ is the most common and important $\mathrm{GHG}$ affected by human activity, and human activity can also cause $\mathrm{CO}_{2}$ to be removed from the atmosphere, for example by creating more forests that absorb more of the gas as they grow.

Methane $\left(\mathrm{CH}_{4}\right)$ and nitrous oxide $\left(\mathrm{N}_{2} \mathrm{O}\right)$ are other examples of human-created GHGs, produced for instance during the combustion of wood and fossil fuels [1]. GHGs have different global warming potentials, a measure of the capacity of each GHG's to trap heat into the atmosphere over a given time frame calculated relative to $\mathrm{CO}_{2}$, which has a global warming potential of 1 . For instance, the global warming potential of $\mathrm{CH}_{4}$ is 25 , meaning that 1 tonne of $\mathrm{CH}_{4}$ traps approximately 25 times more heat than for 1 tonne of $\mathrm{CO}_{2}$ over 100 years.

A reference to carbon is commonly used as a synonymous of GHGs when discussing climate change mitigation. For the sake of simplicity, this approach is used in this document. 


\section{The role of forests in the Carbon balance}

A forest is considered a source of GHGs when it emits more GHGs than it removes from the atmosphere, whereas it is considered a sink when it removes more than it emits [2]. Forest ecosystems and the forest sector comprise various pools amassing or releasing carbon. A carbon pool is a reservoir that stores, captures or releases carbon. The carbon cycle involves transfer of carbon between various pools and the atmosphere.

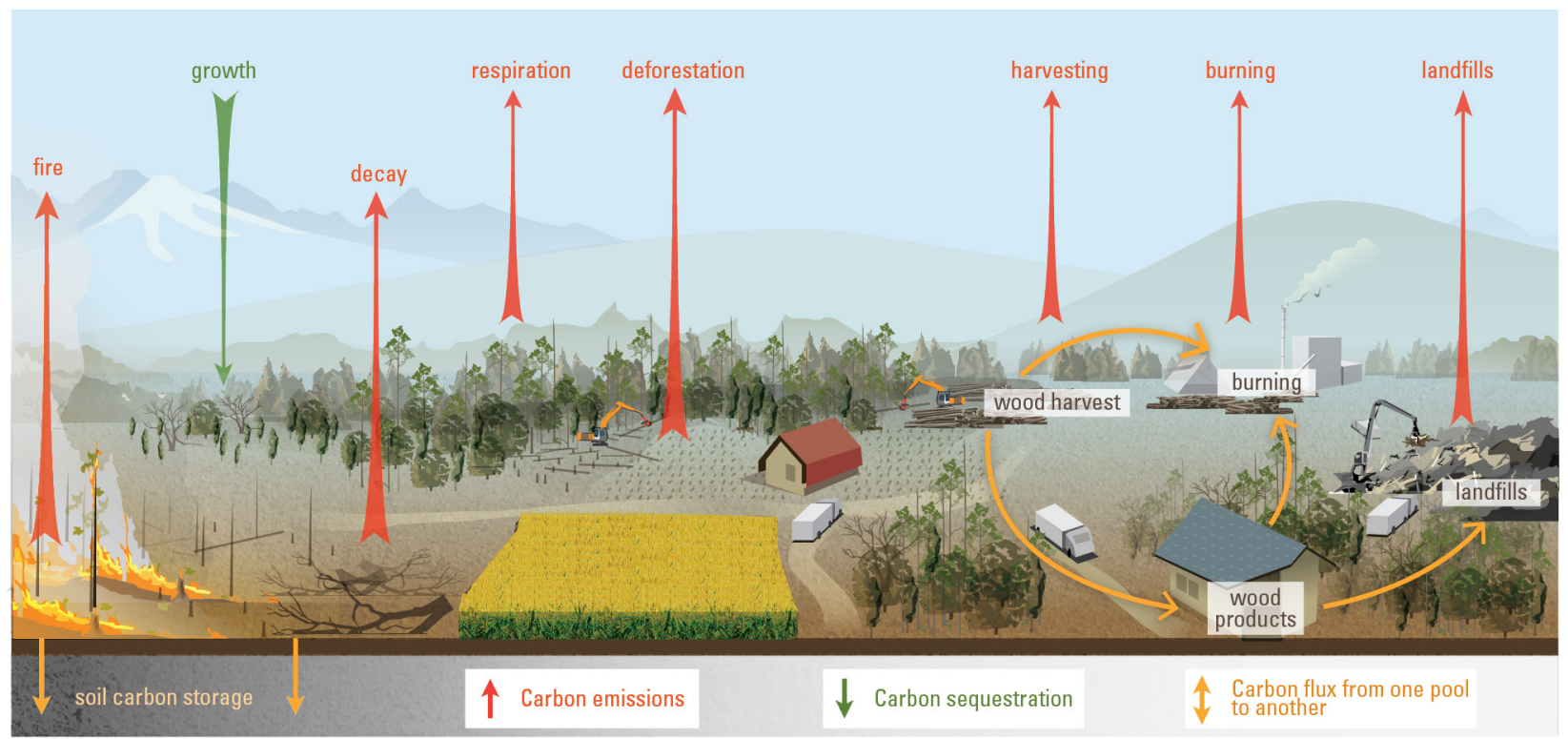

Figure 1. The forest and forest sector carbon cycle [3]. The arrows are not to scale, and the magnitude vary considerably across space and over time.

Growth: Trees accumulate or "sequester" carbon over the long-term through photosynthesis, during which they transform sunlight and $\mathrm{CO}_{2}$ from the atmosphere into organic matter, energy and oxygen.

Respiration: Forests emit carbon in the form of $\mathrm{CO}_{2}$ during respiration by plants and trees.

Decay: The decay of dead organic matter also emits some carbon to the atmosphere (referred to as heterotrophic respiration).

Tree species with faster growing capacity will normally sequester carbon more rapidly. In the first 10 to 20 years after disturbance, forests often can be carbon sources because decomposition of residues and dead organic matter releases more carbon than is taken up through photosynthesis. With time, growth rates increase, decay of residues decreases, and maturing forests become net carbon sinks. As forests grow older their growth potential and associated carbon uptake decreases 
Soil carbon storage: Part of the carbon stored in tree biomass is transferred to dead wood and soil on the forest floor and accumulates there, leading to long-term carbon storage. The transfer occurs as trees loose leaves, needles or other parts, and when they die.

Forest fire: Burning of the forest produces immediate carbon emissions as well as transferring some carbon to deadwood and soils. Other natural disturbance such as insect outbreaks (for example, the mountain pine beetle infestation in large parts of central $\mathrm{BC}$ ) can lead to important release of carbon through decreased growth and increased decay and fire hazard.

Deforestation: The permanent removal of forest cover for other land use such as agriculture and urban development releases carbon to the atmosphere. Wood harvesting followed by forest regeneration is not considered deforestation.

Wood harvesting: Logging (and other forest management activities such as slash burning or fertilization) affect the forest's carbon cycle. At harvest, approximately $40-60 \%$ of the tree biomass (branches, roots and leaves) stays in the forest where it slowly decays or is burned to generate immediate carbon emissions. The rest of the carbon is transferred to wood products, where its fate depends on their usage and disposal.

Burning: Some of the newly harvested trees, harvesting residues, waste from wood products manufacturing and post-use waste wood are burned, sometimes to produce energy, resulting in immediate carbon emissions.

Wood products: Wood products are defined as "wood-based materials that, following harvest, are transformed into commodities such as furniture, plywood, paper and paper-like products or used for energy" [4]. Short-lived (e.g., paper) and long-lived (e.g., lumber, panels) wood products store carbon for varying periods equivalent to the duration of their use.

Landfill: When wood products are no longer needed they are often sent to landfills where their carbon may be stored for a long period of time, but also releasing carbon as $\mathrm{CO}_{2}$ and methane. Even though some of the wood products found in landfills will never decompose, methane emissions could be substantial since methane has a higher global warming potential than $\mathrm{CO}_{2}$. 


\section{Forest Carbon in British Columbia's forests}

BC's 55 million hectares of forests store approximately 6 to 7 billion tonnes of carbon. On average since 1990, it is estimated that BC's forests have removed from the atmosphere an amount of carbon approximately equivalent to that of the annual emissions from all the other sectors of $\mathrm{BC}$ combined ( 64 million tonnes of $\mathrm{CO} 2$ in 2013 [6]). Approximately the same amount of carbon is also transferred annually from the forest to the forest sector carbon pool to meet society's demands for timber, fibre and energy. What is done with these diverse wood products has a significant impact on the provincial carbon balance. An important question thus arises: can changes in BC's forest management and changes in the use of wood harvested in BC contribute to climate change mitigation and help meet GHG reduction targets in the province?

The government of BC reported net forest emissions of 3.1 million tonnes of CO2 in 2013, which represents approximately $5 \%$ of total provincial emissions [6]. However, these net emissions only account for deforestation and afforestation, with the emissions due to deforestation more than offsetting the removals from afforestation. Not included are emissions and removals resulting from processes and activities in the managed forest: net growth minus decay, wildfires, and slash burning (Figure 2). Another important component of BC's forest carbon balance are the emissions resulting from wood harvesting, which need to consider the carbon stored in wood products ("harvesting minus sequestration in wood products" in Figure 2).

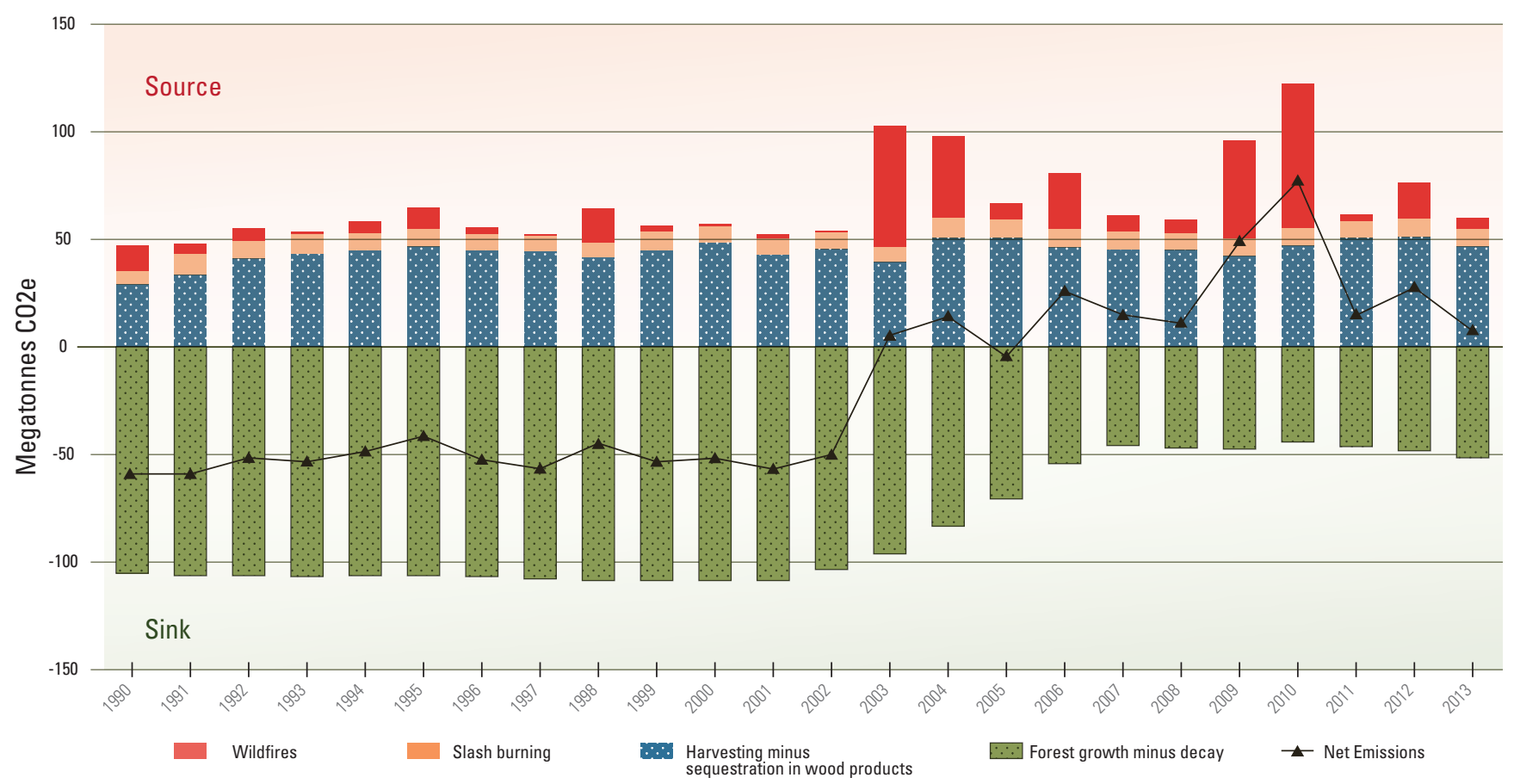

Figure 2. Forest-related emissions and sinks by category from 1990 to 2013 [6]. 
Taking into account these emissions and removals, BC forests were a sink between 1990 and 2002, but became a net carbon source in 2003 and have emitted more than they sequestered since then (except for 2005, see black line in Figure 2). This shift from sink to source is mainly due to an increase in wildfires and the large amount of trees killed by the mountain pine beetle outbreak, which reduce carbon sequestration in the short term while increasing decay (see the green bars in Figure 2) [7]. 


\section{Forest Carbon mitigation options in BC}

Business-as-usual activities in all areas of everyday life and the economy result in GHG emissions and removals. Climate change mitigation involves changing those activities in order to reduce the emissions and increase the removals. Changes in how forests are managed so as to reduce GHG emissions and increase sequestration in the ecosystem are globally acknowledged as a valuable mitigation strategy $[8,9]$ that can also offer additional benefits such as biodiversity and water conservation. It is also important to consider mitigation opportunities from increasing the carbon stored in wood products. And it is important to consider mitigation resulting from increasing substitution of wood products for other products and fossil fuels whose production and use cause more GHG emissions on a life-cycle basis [10].

The use of wood to offset emissions that would have otherwise ensued from using more energyintensive products is referred to as material substitution.

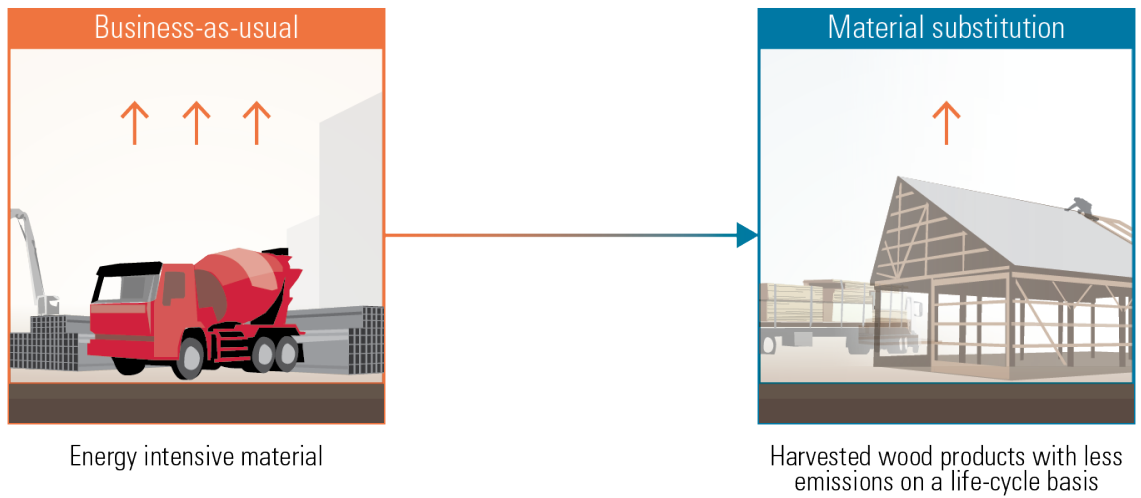

Similarly, energy substitution involves the production of energy with wood biomass instead of using fossil fuels that are more emissions-intensive on a life cycle basis.

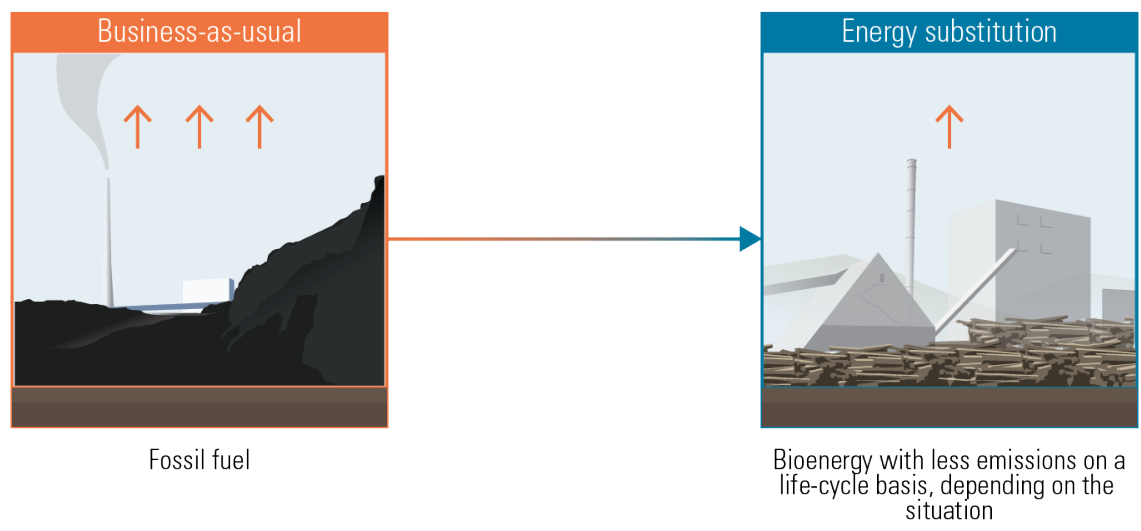


A condition for wood products to provide mitigation potential, however, is that the forests from where they originate be managed sustainably $[11,12]$. It has been shown that forest growth plus carbon stored in wood products originating from a sustainably managed "second growth" forest over a rotation period can be equal or superior to the carbon loss due to logging activities and decomposition [13].

A "systems perspective" that takes into account how a mitigation strategy affects each of these three elements - forest emissions and removals, storage of carbon in wood, and substitution effects will provide an understanding of its net effect on emissions and removals. This perspective will also provide an understanding of the trade-offs between increasing carbon storage in forest ecosystems and seeking to obtain mitigation benefits through use of wood [14, 15].

Mitigation strategies in the forest sector either enhance or maintain carbon storage or reduce carbon sources. They can be classified into three main categories:

(1) maintain or increase forest areas,

(2) maintain or increase forest carbon density (the amount of carbon stored per hectare of forest), and

(3) increase the use of wood.

Each of these categories is discussed in detail in the following pages. While this document focuses on mitigation impacts, it is clear that other factors also need to be taken into account, including for instance habitat conservation, water quality or job creation. The figures here and on subsequent pages who generic representation of emissions (arrows pointing upward in the diagram) and removals (arrows pointing downward). 


\section{Maintain or increase forest areas}

This first category of forest-related mitigation strategies refers to the preservation of existing forests or the increased creation of new forests through afforestation.

\subsection{Avoid deforestation}

Deforestation is the removal of forest and the conversion of the land to another long-term use. In $\mathrm{BC}$, deforestation is mainly caused by agriculture, urban development and energy development [16]. Avoiding deforestation preserves the forest, the carbon stored it in, and its future potential to remove carbon from the atmosphere. Where deforestation does occur, it can be possible to reduce the resulting GHG emissions by changing deforestation practices and the use of wood. Where deforestation is unavoidable, an equivalent area of forest can be afforested elsewhere to achieve a net zero deforestation rate.

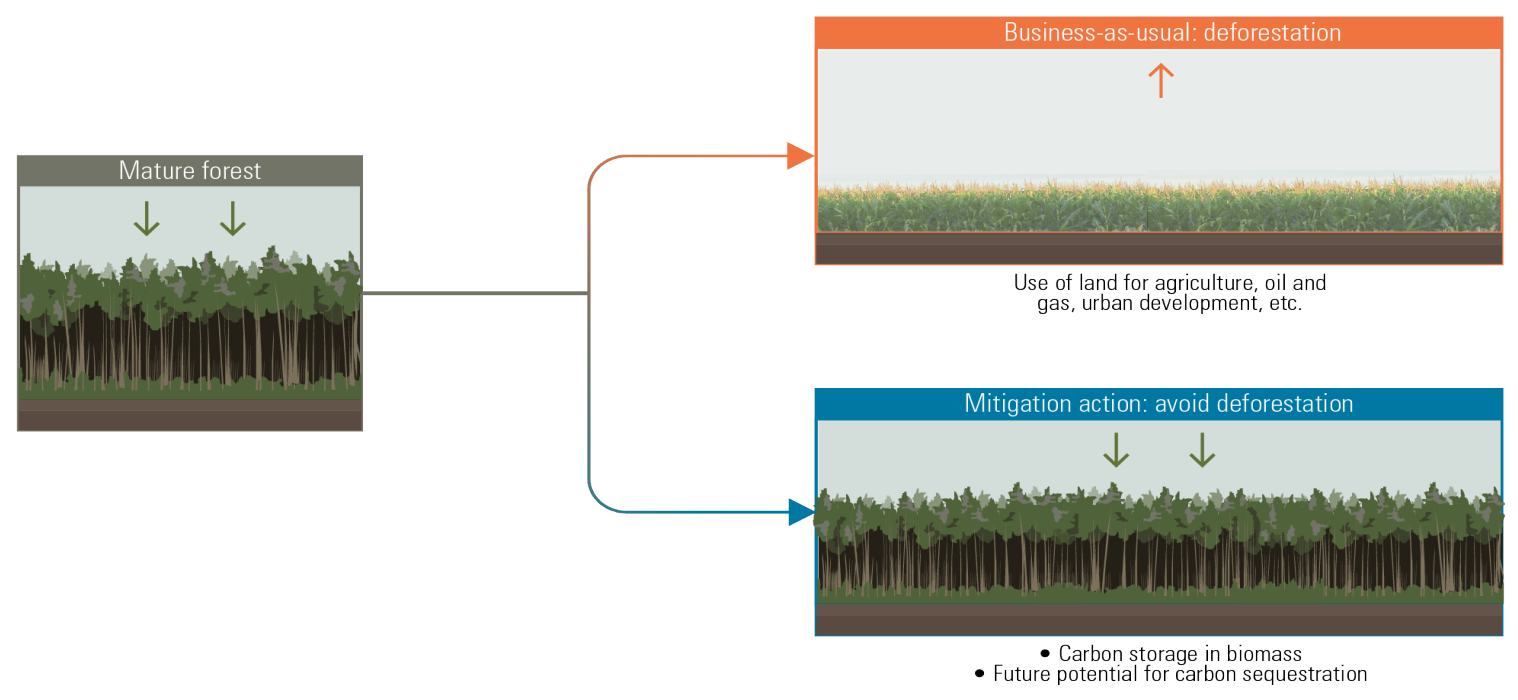




\subsection{Increase Afforestation}

Afforestation converts non-forest land to forest. In BC it involves the establishment of trees through planting or seeding on land that has not been forest for at least 20 years. It results in carbon sequestration in tree biomass, dead wood, litter and soil. The carbon benefits slowly accumulate over time as trees grow.

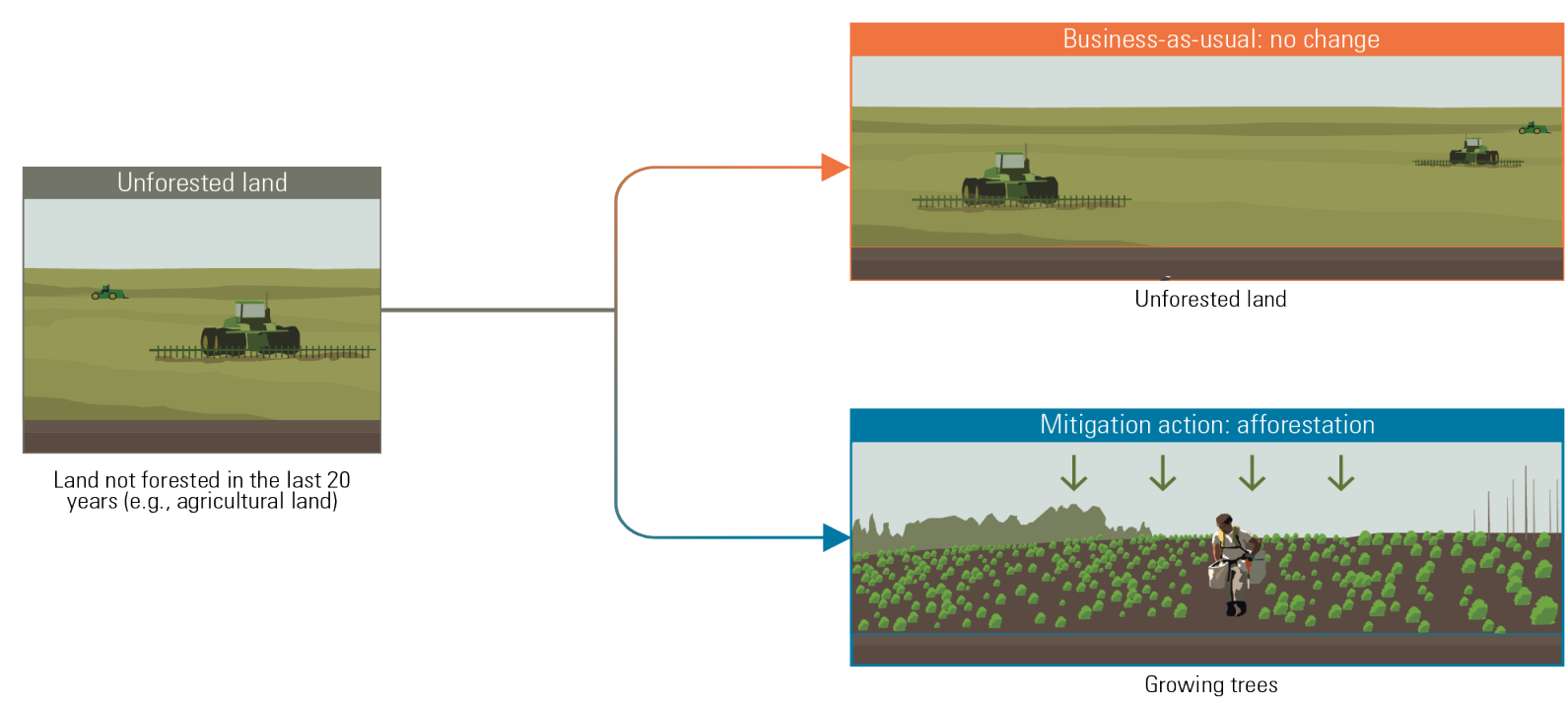

The potential for afforestation in $\mathrm{BC}$ is mainly on marginal or degraded agricultural land. Historically, afforestation activities have occurred at low levels in BC. However, interest is growing because of benefits associated with fibre production, environmental conservation and possible revenues from the sale of carbon credits [17]. 


\section{Maintain or increase forest carbon density}

The second mitigation category involves maintaining or increasing forest carbon density, referring to the amount of carbon per hectare of forest. To do so, various forest management strategies can be implemented, including various forest conservation approaches as well as silvicultural activities that increase growth rates and carbon uptake of trees, harvesting practices that reduce carbon losses (e.g. avoided slashburning) and efforts to reduce the impacts of natural disturbances.

\subsection{Increase forest conservation, use longer forest rotations or harvest less}

Natural, old forests typically store more carbon than managed forests because they have a greater proportion of older trees with high carbon density [18]. Reducing harvest volume and/ or restricting the area available for harvest through reductions in allowable cut, requiring longer rotations and increasing reserve areas therefore should result in forested landscapes with higher carbon density than managed areas [19].

However, adopting such strategies can lead to "leakage", i.e. an increase in harvest rates elsewhere which should be considered when examining the net mitigation impact [20]. In addition, a reduction in timber harvesting generates trade-offs between increasing carbon storage in forest ecosystems or in wood products:

"a conservation strategy with no or limited harvest is expected to yield landscapes with high carbon density (but lower uptake rates), whereas a strategy that involved intensive management will yield a forest landscape with a lower carbon density but a higher carbon uptake rate. The difference between the two strategies is the rate at which harvested biomass carbon is provided to meet society's demand" [15].

Reductions in harvest also can reduce substitution benefits, if the use of wood products is replaced by the use of products whose production, use and disposal are more emissions-intensive on a life cycle basis. 


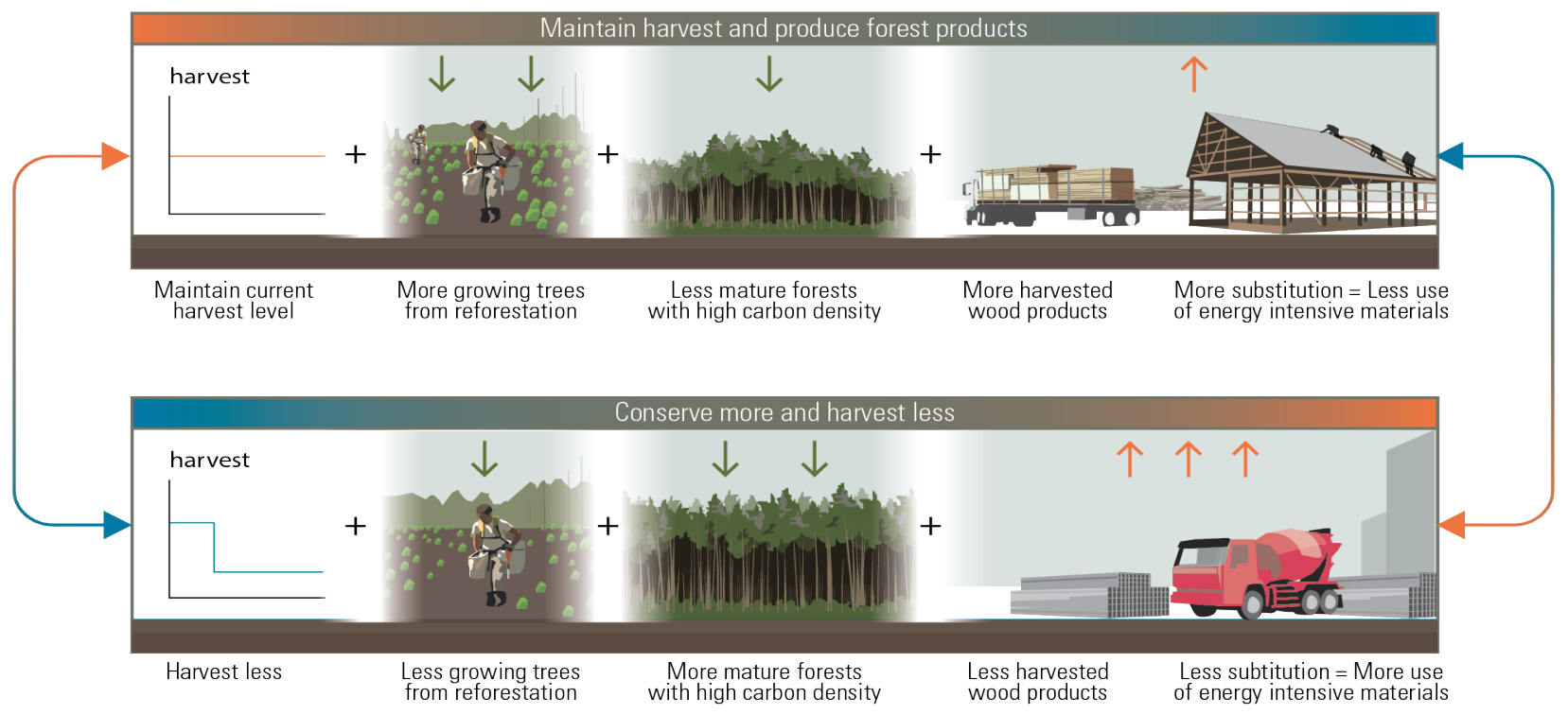

The frequency of natural disturbances represents an important factor to consider in any forest mitigation strategy, as is the forecast that climate change will increase natural disturbance rates. For instance, the high frequency of fires and pest outbreaks in BC's boreal and interior forests often prevents them from reaching and maintaining their theoretical maximum carbon density [1]. In contrast, BCs coastal temperate rainforests are characterized by very infrequent natural disturbances and high carbon density [19-21]. Consequently, for mitigation purposes, conservation-oriented strategies could make most sense in forests with low natural disturbance rates and high carbon density. Simultaneously it could make sense to intensify the management of forests with frequent natural disturbances where conservation is less feasible for mitigation purposes, so as to increase their productivity. 


\subsection{Implement more intensive forest management}

Intensive silviculture such as the use of seeds selectively chosen for their improved growth characteristics, fertilization and other site enhancement strategies can increase post-harvest growth rates and therefore carbon density. For example, it has been observed that the use of improved seeds chosen for high growth characteristics in Douglas-fir coastal forests in BC led to greater tree volume gains [22]. Similarly, fertilization has been shown to enhance tree growth and carbon uptake in nitrogen-limited boreal forests in Northern BC [23]. In general, these strategies have a slow response because trees take time to grow, meaning that mitigation benefits will only accumulate slowly.

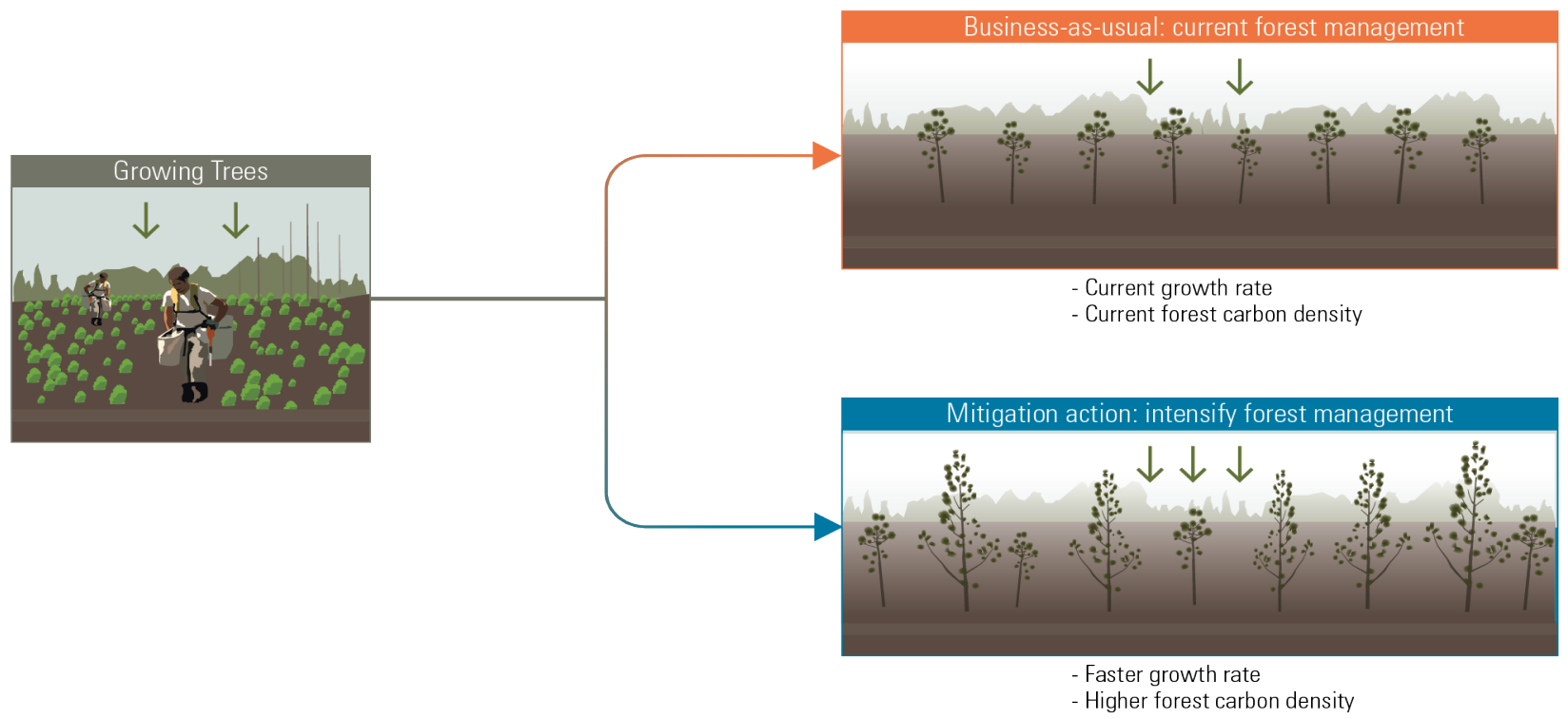




\subsection{Change harvesting practices}

\section{Increase utilization and efficiency at harvest}

Currently, harvesting residues are mainly left to decay or to be burned on site. Possibilities exist to increase the utilization of wood from harvest cut blocks - i.e. remove more of the wood on each hectare harvested - which will reduce the amount of harvesting residues [19]. The additional wood removed might not be of the same quality as the rest of the harvest but because more wood is extracted per hectare it might be possible to reduce the area harvested or, alternatively, the total harvest could increase.

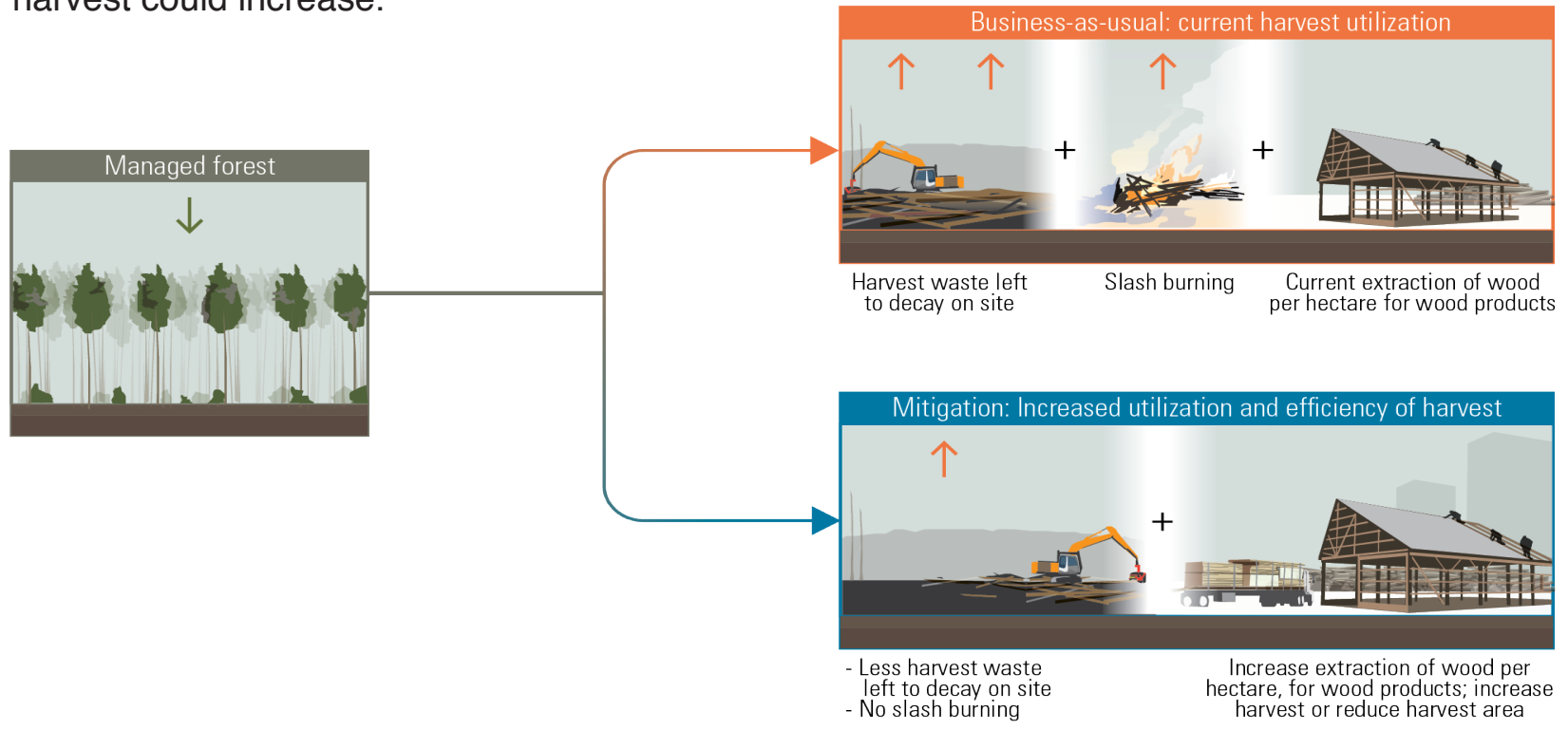

\section{Remove harvest residues for wood products or energy}

Some of the harvesting residues could be collected to produce wood products or bioenergy to replace other products or fossil fuels that are more emissions intensive on a life cycle basis. If the residues would have been burned in the forest (i.e. slash burning) then these emissions will be avoided if the residues are instead collected and used for products or energy.

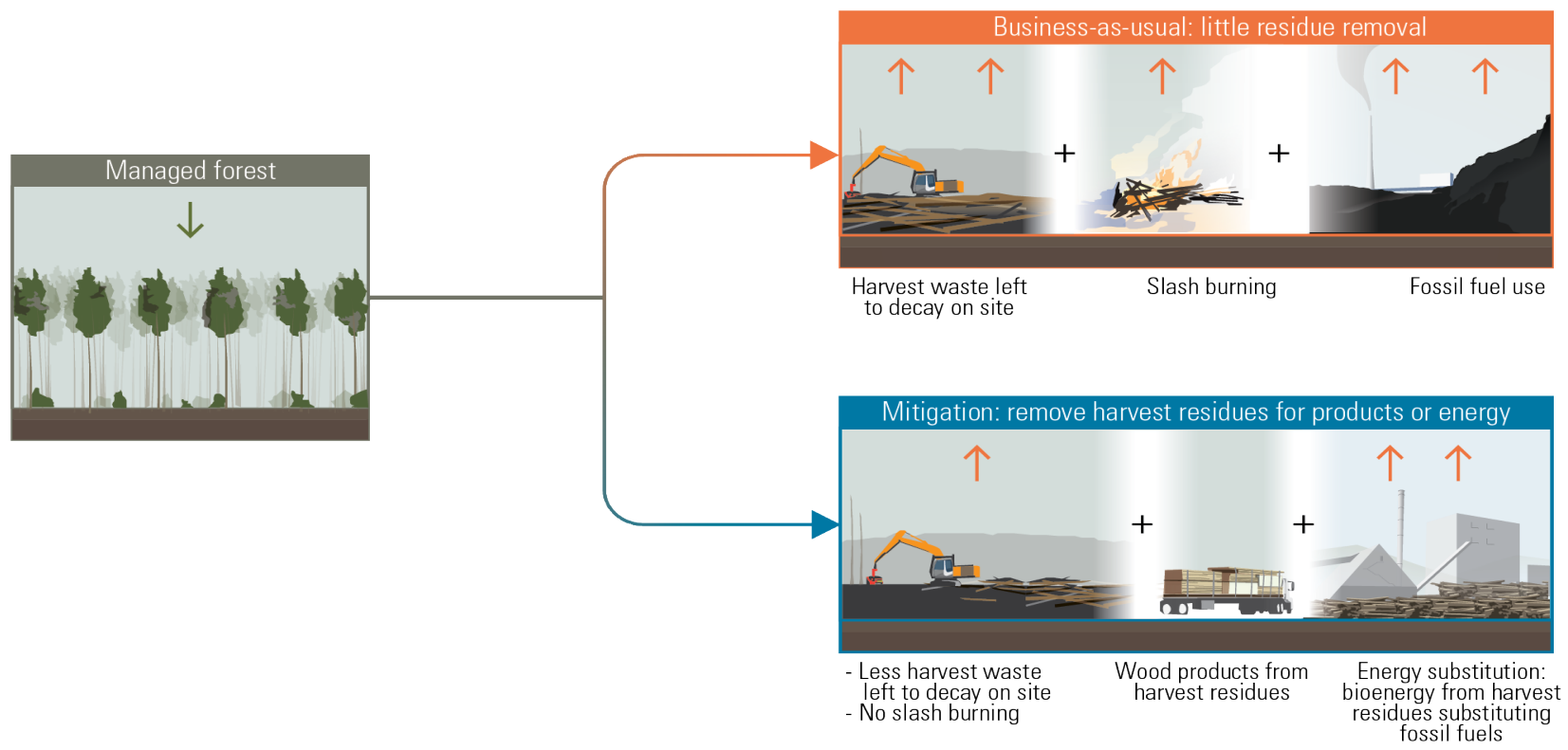




\section{Salvage harvesting}

Salvage harvesting refers to the harvesting of trees in forests affected by natural disturbances such as fire and insects. When natural disturbances kill trees the risk of forest fire is increased and emissions associated with decay on site rises. In such cases, salvage logging can reduce risks of wildfire. Furthermore, harvesting trees already killed because of natural disturbances means that harvesting of live trees could be reduced, assuming that the wood could be used for the same purpose in terms of forest products.

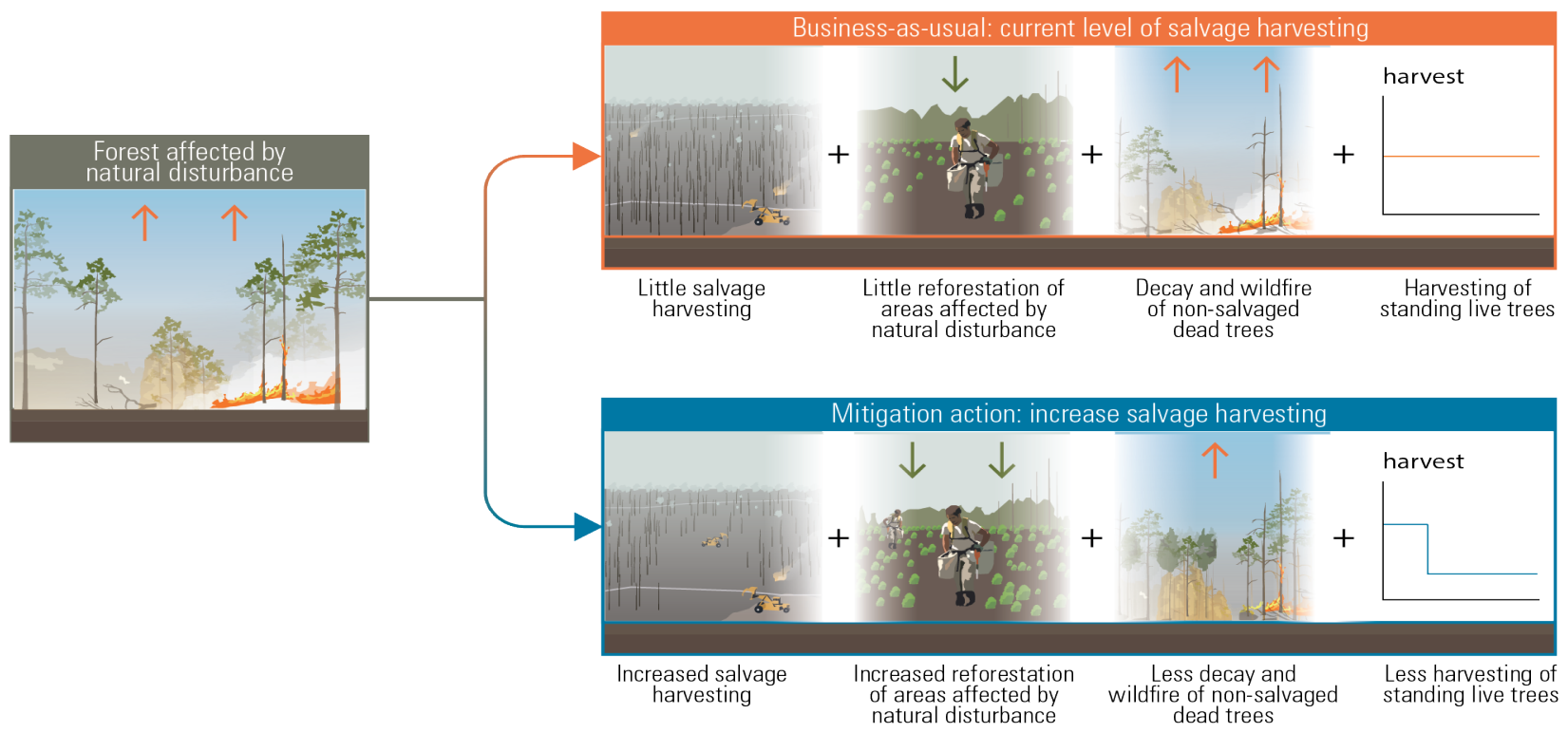

In other situations salvaged wood cannot be used to produce the same products as standing-live trees. In such cases there might be opportunities for new uses of the salvaged wood, such as bioenergy. For instance, the current widespread mortality caused by the mountain pine beetle infestation in BC's interior region increased dramatically the proportion of dead trees. These trees release carbon through decay and represent fire hazards. For mitigation, some of the trees could be salvaged for the production of bioenergy and the forest rehabilitated with reforestation [24].

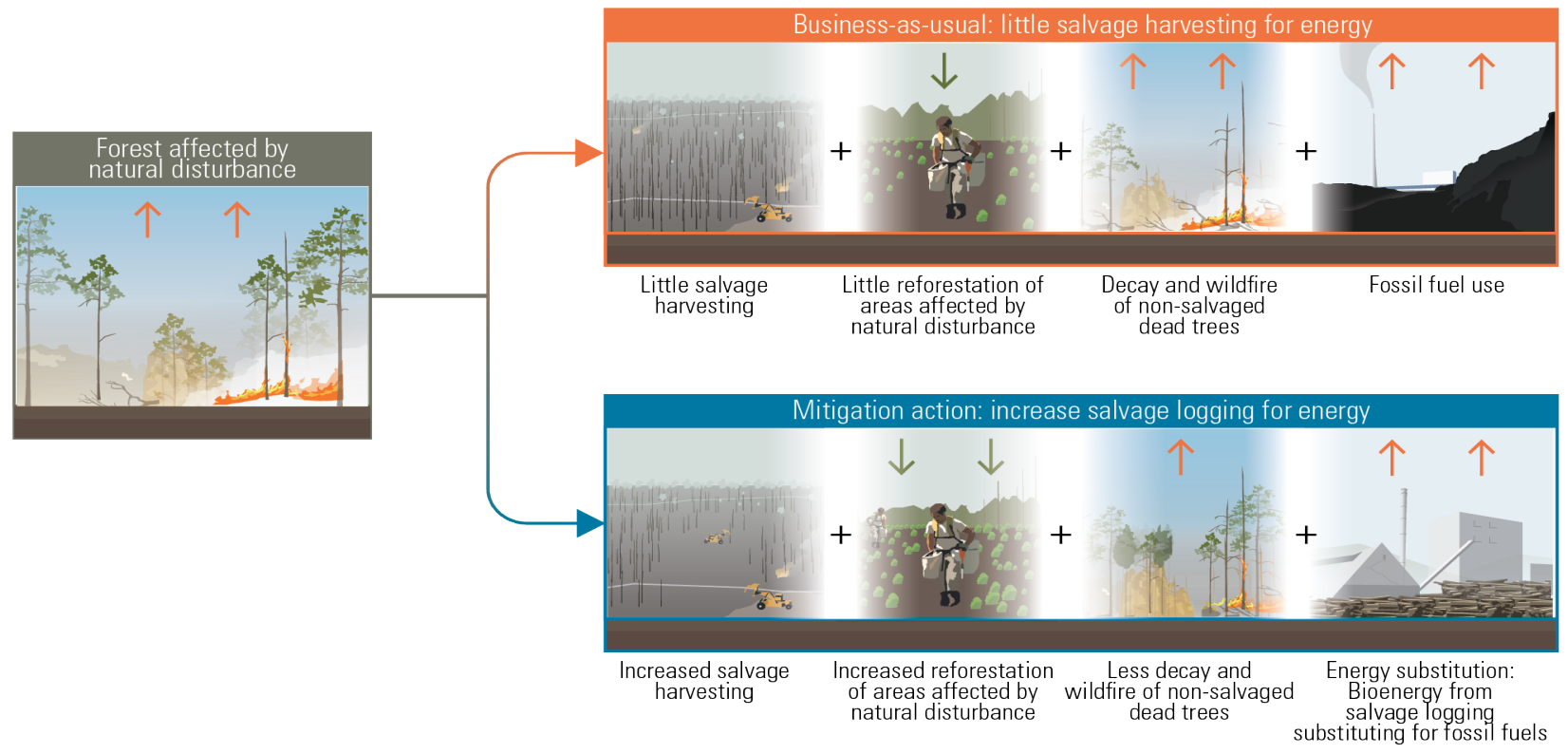




\subsection{Reduce the impacts of natural disturbances}

Wildfire suppression can reduce the area burned and the emissions that result. Techniques to reduce the fuels for forest fires, such as thinning stands, removing deadwood, salvage logging and prescribed fires can reduce the risk and severity of wildfires [25]. Similarly, successful efforts to suppress insects could have the same effect.

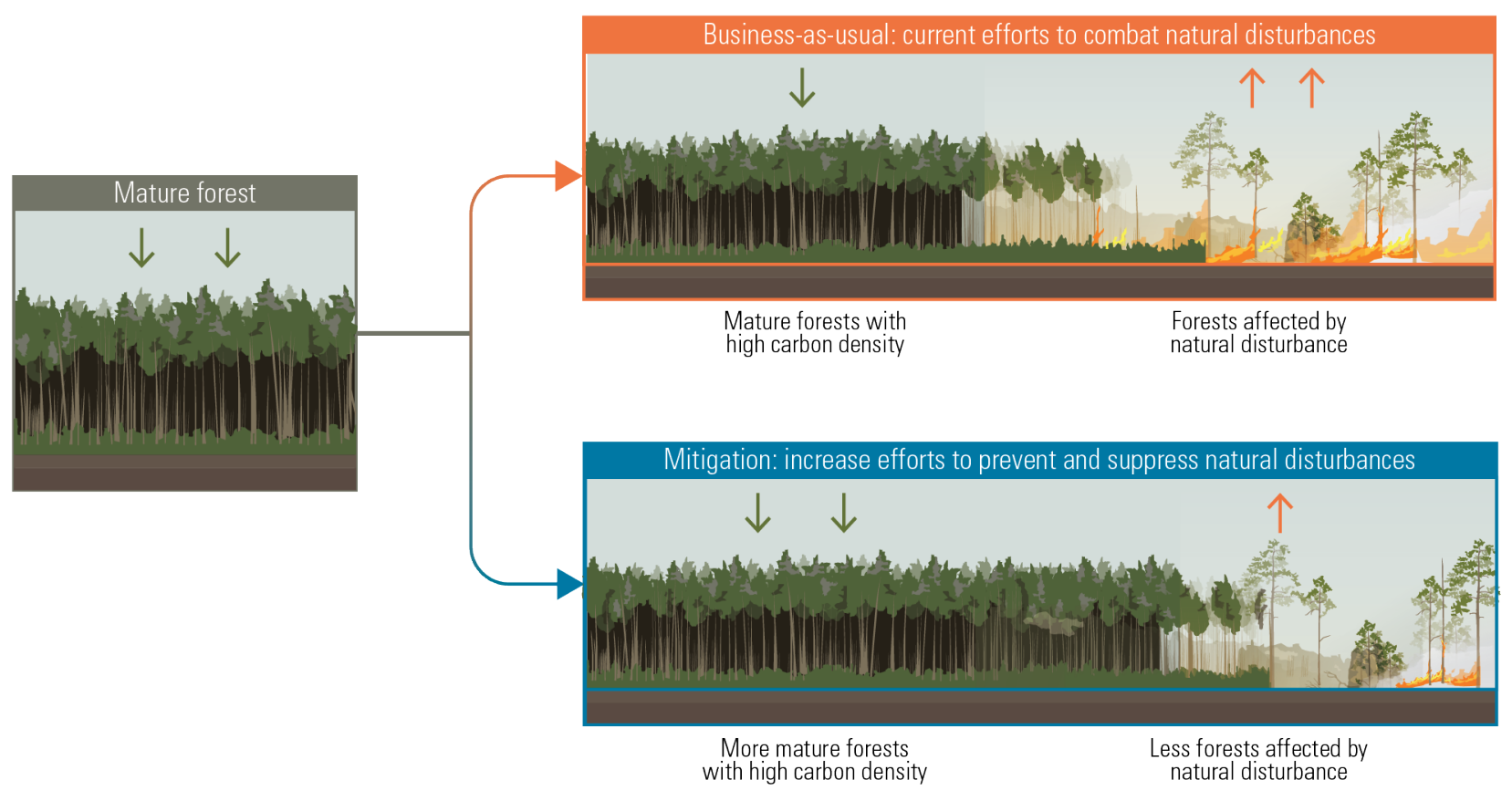

Climate change is expected to have significant impacts on BC's forests. Forest management strategies that aim to reinforce natural resilience of forests to disturbance and increase their adaptability to climate change could also contribute to mitigation. For instance, a recent study forecasts important changes in zones of climatic suitability for BC tree species, suggesting that assisted migration of tree species can help improve resilience [26]. 


\subsection{Rehabilitate underproductive sites}

In $\mathrm{BC}$, logging is rapidly followed by mandatory reforestation. While such reforestation is not considered as a mitigation strategy since it is legally required, the acceleration of reforestation through increased use of tree planting or the rehabilitation of underproductive sites outside of forest industry obligations do provide additional mitigation opportunities. For instance, forest companies are not responsible for reforesting areas damaged by insect infestation where they do not carry out logging activities. The rehabilitation of such sites could increase carbon sequestration and reduce the emissions caused by increased decay and wildfires due to the trees killed by insects.

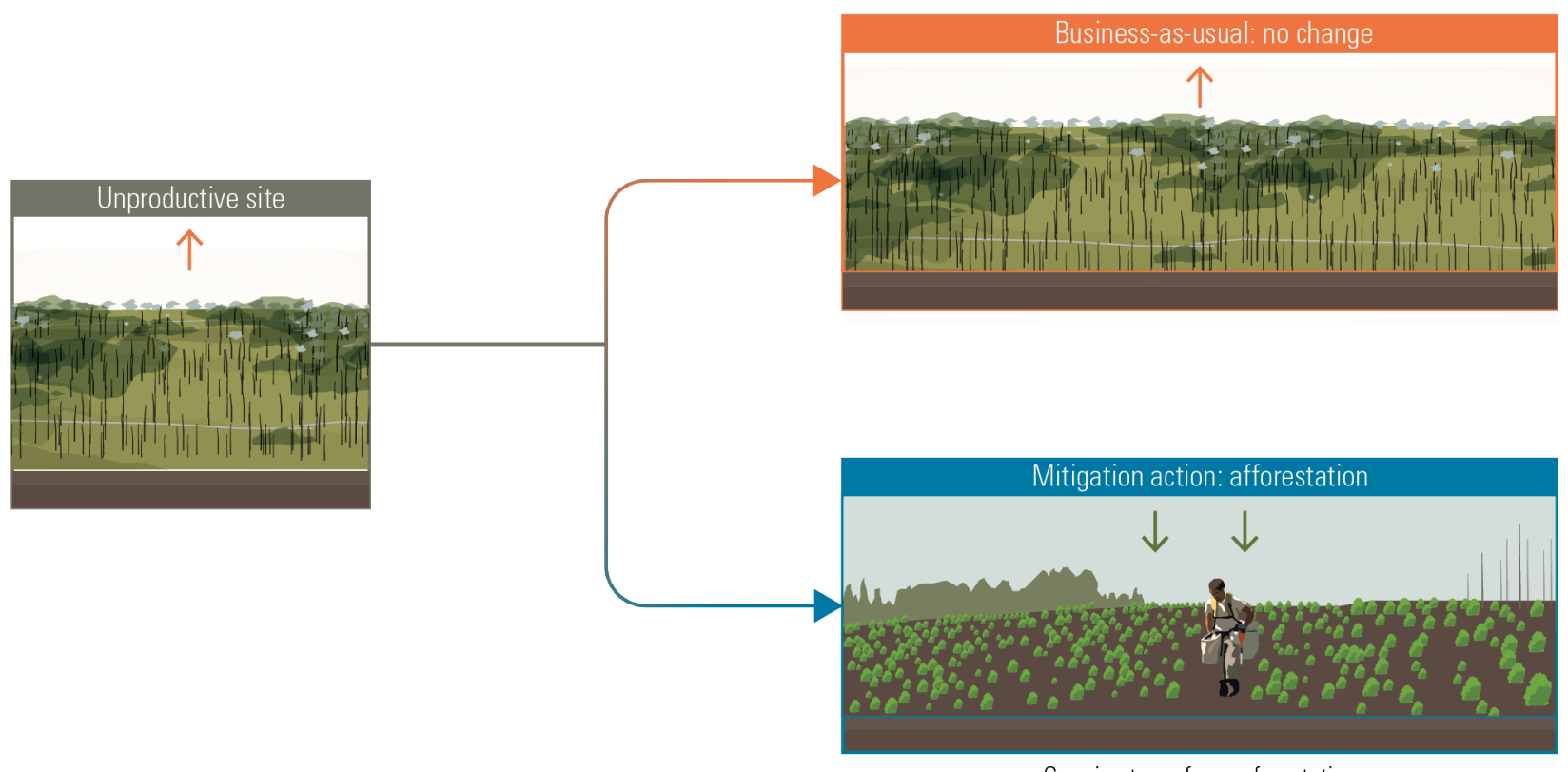

Growing trees from reforestation 


\section{Use more wood}

The third group of strategies for forest-related mitigation involves the use of wood. To analyse the impact of wood products on atmospheric carbon, one has to evaluate a product's whole life cycle, from extraction to end-of-life management. The three main mitigation opportunities related to wood products are

(1) increasing the time that carbon is stored in wood products,

(2) increasing avoided emissions through increased material substitution, and

(3) improving end-of-life management of the products.

\subsection{Produce more long-lived wood product}

The time over which carbon is stored in wood products depends on the products' life duration. Some products have very short useful life, such as paper (2.5 years), whereas others have longerterm carbon storage potential such as the lumber encountered in single family homes ( $>75$ years) and commercial buildings (>90 years) [27]. If relatively more of the harvest is used for long-lived products the carbon will remain out of the atmosphere for longer.

\subsection{Increase material substitution}

Wood can substitute for various products with higher GHG emission impacts on a life-cycle basis (e.g., steel studs, concrete walls and floors, cement). For instance, the use of steel or concrete framing instead of wood in houses in the USA was shown to lead to $26 \%$ and $31 \%$, respectively, more GHG emissions than the use of wood [28]. The life-cycle emissions of wood need to be considered relative to the life cycle emissions of the alternative products. The increase in wood for material substitution could come from using more of the harvest, or increasing the harvest. This would affect the total life-cycle benefit of the substitution.

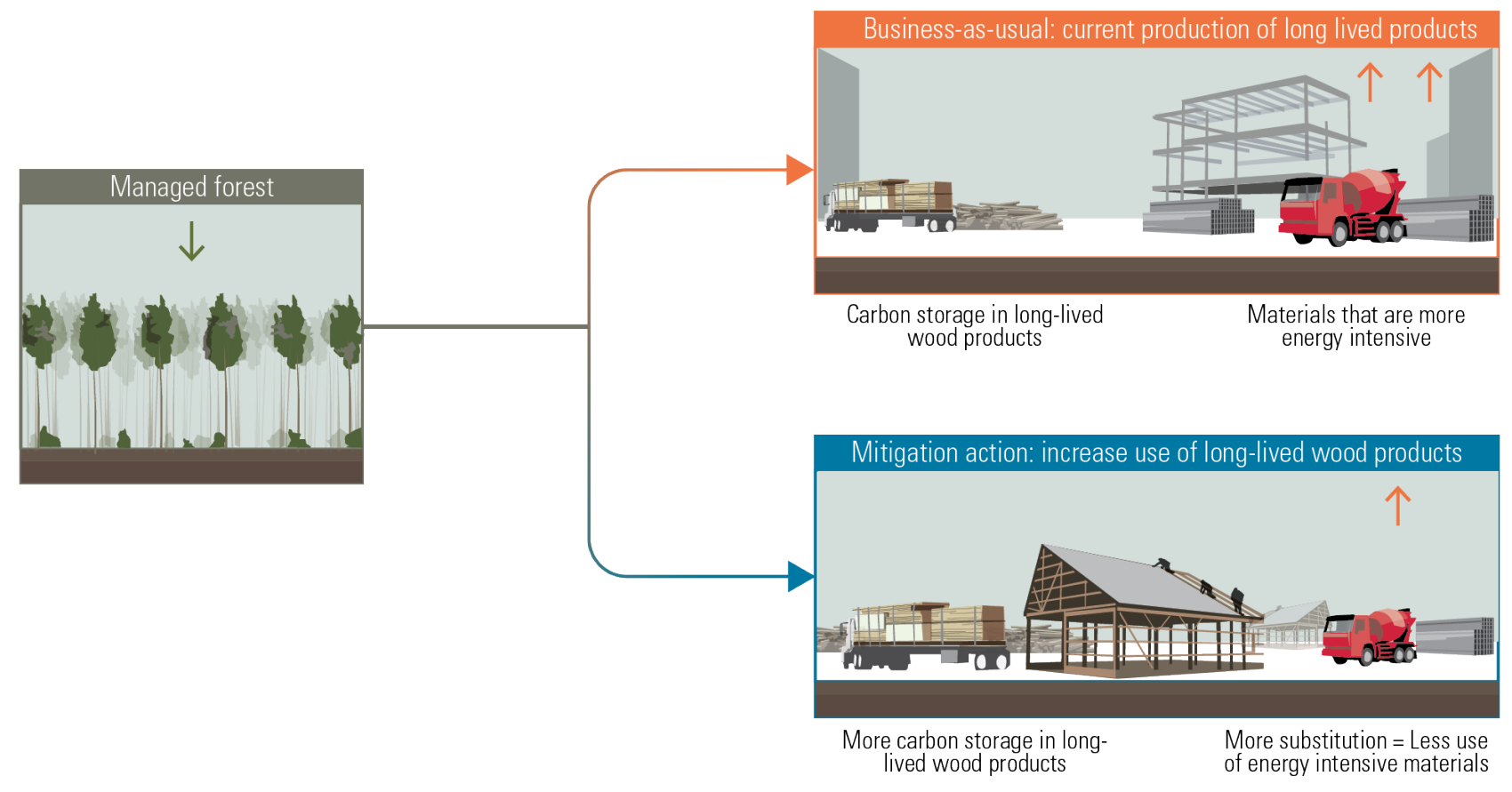




\subsection{Changing end of life management}

When wood products reach the end of their useful life, they can be deposited in landfills, recycled or burned to produce energy [27]. Use of wood for bioenergy is discussed in the next section.

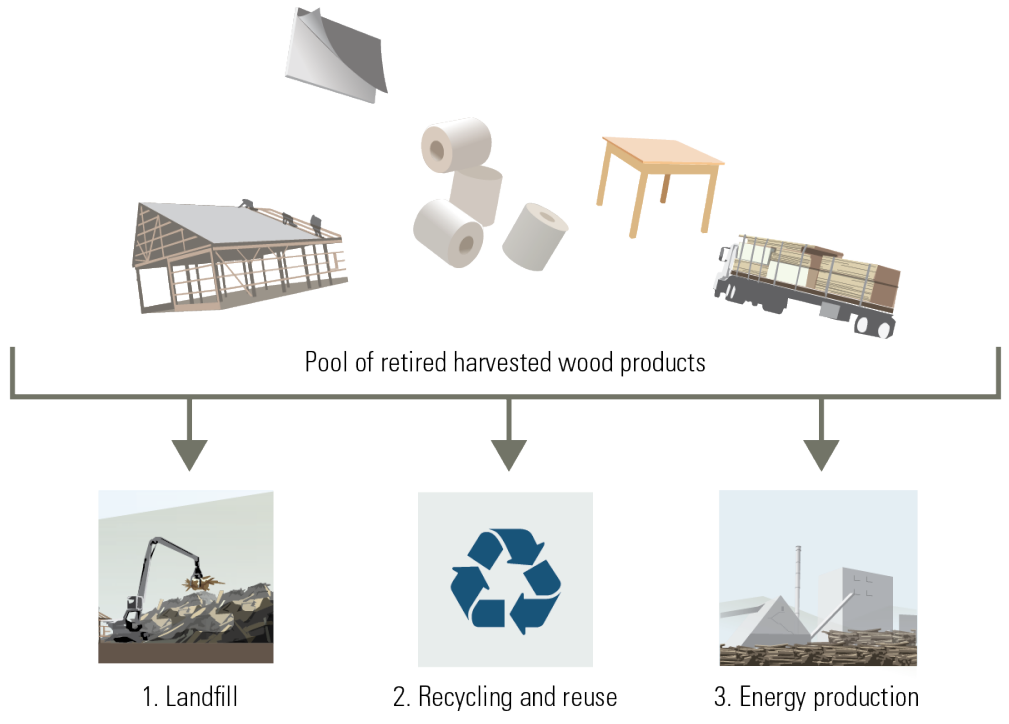

\section{Landfills}

Some of the wood sent to landfills will never decompose, but some of it will, resulting in methane emissions. Consequently, diverting wood (and other organic matter) from landfills and improved landfill management practices allowing for the capture and combustion of methane can reduce GHG emissions.

\section{Recycling and re-use}

Even though improved waste management technologies can provide mitigation opportunities, recycling wood products generally is considered to be better for mitigation [12]. Recycling extends the use of the wood, keeping the carbon out of the atmosphere for longer, increasing the potential for reduced emissions from material substitution, and avoiding potential methane emissions resulting from decay in landfills [10]. Recycling short-lived products such as paper allows the forest industry to refocus their production on long-lived products. 


\subsection{Increase production of bioenergy using wood}

The production of energy from forest biomass can reduce emissions on a life-cycle basis when the bioenergy replaces fossil fuels (energy substitution). This can be attractive for mitigation purposes in many, but not all circumstances. Whether there are mitigation benefits, and the magnitude of the benefits, depend on various situation-specific factors: the type of biomass; the businessas-usual use of the biomass and the business-as-usual energy source; and the efficiency with which the biomass is used for energy compared to the efficiency of the business-as-usual energy source.

Taking all of these factors into account typically shows that switching to bioenergy initially results in more emissions than the fossil fuel it replaces. Under the right circumstances, the bioenergy will eventually reach a "break-even point" at which the bioenergy starts to have a net positive mitigation effect. Depending on the circumstances, this could take from as little as a year or less to many decades, and in some cases the break-even point may never be reached.

The carbon benefits of using biomass-derived energy and the delay until reaching the break-even point depend mostly on (1) the source of the biomass and (2) the source of the displaced energy.

\section{Source of the biomass}

The wood biomass used to produce bioenergy can originate from various sources.

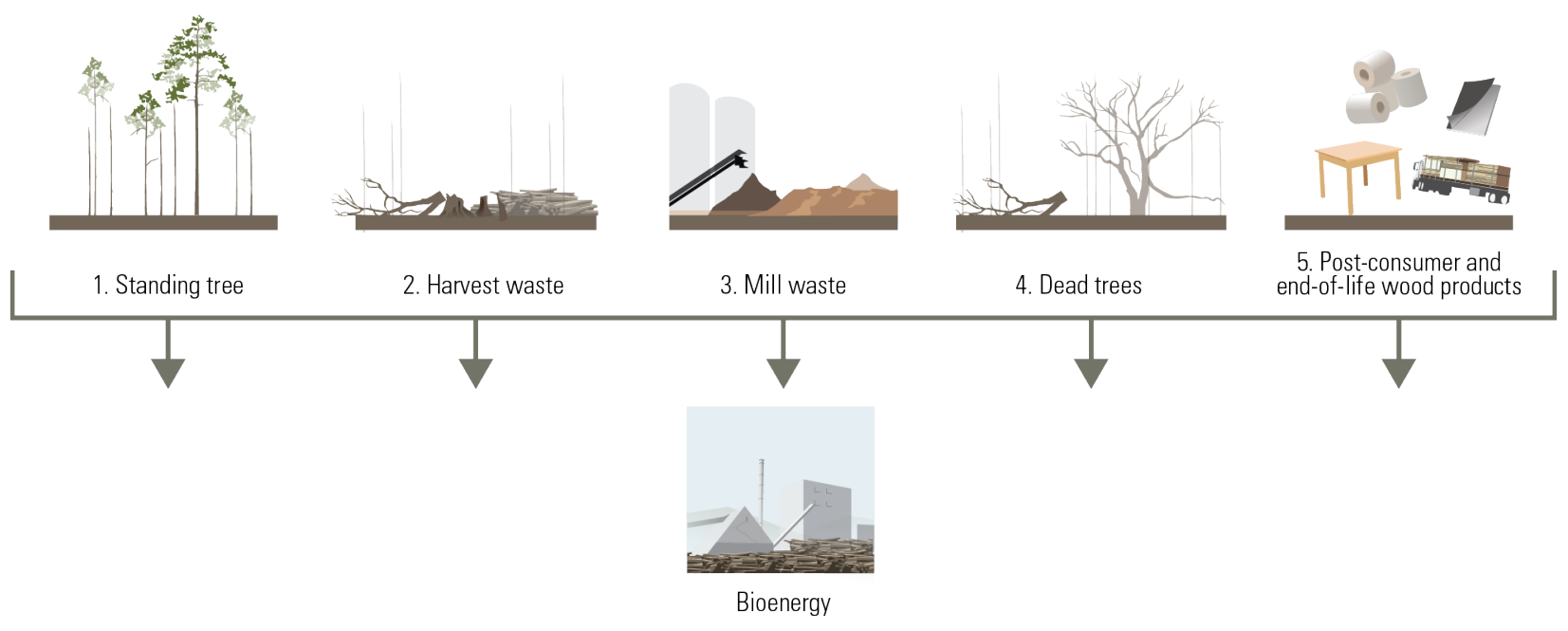


Standing live trees typically would not be harvested for bioenergy in BC since they typically provide greater mitigation potential when used in long-lived wood products rather then to produce energy, which offers no or very little emission reductions [3,29]. However, some exceptions could justify logging trees for bioenergy, as in the case of off-the-grid remote communities that are using emission-intensive energy sources like diesel [30]. The use of harvesting and mill residues as well as post-consumer and end-of-life wood products for bioenergy offers a better mitigation opportunities than standing live trees since the carbon in the residues or wood products would otherwise be emitted to the atmosphere, either progressively through decay or immediately through burning, whereas standing live trees continue to stock and remove carbon from the atmosphere. Even though mill residue management has tremendously improved in the last years in BC, some waste is still burned without energy production, indicating improvement opportunities [31]. Finally, the drastic increase in deadwood generated by the mountain pine beetle outbreak and by increased forest fires creates mitigation opportunities to salvage dead wood to produce bioenergy.

\section{Source of the displaced energy}

The substitution effect increases when biomass replaces high emission fossil fuels such as coal instead of less carbon-intensive sources like natural gas. A study in Ontario showed that the break-even point was 16 years when using forest harvest residues to substitute for coal as an energy source, and 74 years when substituting for natural gas [32]. 


\section{Mitigating climate change through actions in BC's forest sector}

The mitigation strategies discussed in this document are diverse, and some options could be implemented together, while other could not. The mitigation potential such strategies needs to be determined using a systems approach that takes into account the net emissions impact in terms of the effects on emissions/removals in the forest, on wood products emissions, and on avoided emissions through substitution of wood for other products and fossil fuels.

Strategies would need to be considered carefully to weigh their climate effectiveness, economic efficiency, social impacts, implications for other forest values, and administrative feasibility. For instance, a strategy aimed at maximizing carbon mitigation might not maximize biodiversity conservation or local economic development and job creation. Conversely, a strategy that does not provide substantial mitigation might provide substantial job creation. The contributions of BC's forest sector to GHG emission reductions will only be successful if informed by the best science and the perspectives and preferences of the public and different stakeholders. 


\section{References}

1. Dymond, C.C. and Spittlehouse, D.L., Forest in a Carbon-constrained World. Extension Note 92. 2009, Minitry of Forests and Range Forest Science Program. p. 1-10.

2. Natural Resources Canada. Is Canada's Forest a Carbon Sink or Source? . Canadian Forest Service Science Policy Notes 2007 [cited 2015 March 5]; Available from: http://cfs.nrcan. gc.ca/pubwarehouse/pdfs/27501.pdf.

3. BC MFLNRO, Climate mitigation potential of British Columbian forests: Growing carbon sinks. 2013, Government of British Columbia. p. 1-29.

4. Kurz, W.A., Stinson, G., Rampley, G.J., Dymond, C.C., and Neilson, E.T., Risk of natural disturbances makes future contribution of Canada's forests to the global carbon cycle highly uncertain. Proceedings of the National Academy of Sciences, 2008. 105(5): p. 1551-1555.

5. UNFCCC, Estimation, reporting and accounting of harvested wood products. Technical Paper FCCC/TP/2003/7. 2003.

6. BC MOE. British Columbia Greenhouse Gas Inventory: B.C. Greenhouse Gas Emissions 2013. 2015 [cited 2015 September 8]; Available from: http://www2.gov.bc.ca/gov/content/ environment/climate-change/reports-data/provincial-ghg-inventory-report-bc-s-pir.

7. Kurz, W.A., Dymond, C.C., Stinson, G., Rampley, G.J., Neilson, E.T., Carroll, A.L., Ebata, T., and Safranyik, L., Mountain pine beetle and forest carbon feedback to climate change. Nature, 2008. 452(7190): p. 987-990.

8. IPCC, Agriculture, Forestry and Other Land Use (AFOLU), in Climate Change 2014: Mitigation of Climate Change. Contribution of Working Group III to the Fifth Assessment Report of the Intergovernmental Panel on Climate Change, Edenhofer, O., Pichs-Madruga, R., Sokona, Y., Farahani, E., Kadner, S., Seyboth, K., Adler, A., Baum, I., Brunner, S., Eickemeier, P., Kriemann, B., Savolainen, J., Schlömer, S., Stechow, C.v., Zwickel, T., and Minx, J.C., Editors. 2014, Cambridge University Press: Cambridge, UK and New York, NY, USA.

9. IPCC, Climate Change 2014: Mitigation of Climate Change. Contribution of Working Group III to the Fifth Assessment Report of the Intergovernmental Panel on Climate Change. 2014, Cambridge, UK and New York, NY, USA: Cambridge University Press.

10. Malmsheimer, R.W., Bowyer, J.L., Fried, J.S., Gee, E., Izlar, R.L., Miner, R.A., Munn, I.A., Oneil, E., and Stewart, W.C., Managing forests because carbon matters: Integrating energy, products, and land management policy. Journal of Forestry, 2011. 109: p. S7-S51.

11. Sathre, R. and O'Connor, J., Meta-analysis of greenhouse gas displacement factors of wood product substitution. Environmental Science \& Policy, 2010. 13(2): p. 104-114. 
12. Lippke, B., Oneil, E., Harrison, R., Skog, K., Gustavsson, L., and Sathre, R., Life cycle impacts of forest management and wood utilization on carbon mitigation: knowns and unknowns. Carbon Management, 2011. 2(3): p. 303-333.

13. Sathre, R., Gustavsson, L., and Bergh, J., Primary energy and greenhouse gas implications of increasing biomass production through forest fertilization. Biomass and Bioenergy, 2010. 34(4): p. 572-581.

14. Nabuurs, G.J., Masera, O., Andrasko, K., Benitez-Ponce, P., Boer, R., Dutschke, M., Elsiddig, E., Ford-Robertson, J., Frumhoff, P., Karjalainen, T., Krankina, O., Kurz, W.A., Matsumoto, M., Oyhantcabal, W., Ravindranath, N.H., Sanchez, M.J.S., and Zhang, X., Forestry, in Climate Change 2007: Mitigation. Contribution of Working Group III to the Fourth Assessment Report of the IPCC, Metz, B., Davidson, O.R., Bosch, P.R., Dave, R., and Meyer, L.A., Editors. 2007, Cambridge University Press: Cambridge, United Kingdom and New York, USA. p. 541-584.

15. Lemprière, T.C., Kurz, W.A., Hogg, E.H., Schmoll, C., Rampley, G.J., Yemshanov, D., McKenney, D.W., Gilsenan, R., Beatch, A., Blain, D., Bhatti, J.S., and Krcmar, E., Canadian boreal forests and climate change mitigation. Environmental Reviews, 2013. 21(4): p. 293321.

16. BC MOE, British Columbia Greenhouse Gas Inventory Report 2012. 2014, Government of $\mathrm{BC}$.

17. Dominy, S.W.J., Gilsenan, R., McKenney, D.W., Allen, D.J., Hatton, T., Koven, A., Cary, J., Yemshanov, D., and Sidders, D., A retrospective and lessons learned from Natural Resources Canada's Forest 2020 afforestation initiative. The Forestry Chronicle, 2010. 86(3): p. 339-347.

18. Kurz, W.A., Beukema, S.J., and Apps, M.J., Carbon budget implications of the transition from natural to manged disturbance regimes in forest landscapes. Mitigation and Adaptation Strategies for Global Change, 1998. 2(4): p. 405-421.

19. Smyth, C.E., Stinson, G., and Neilson, E., Quantifying the biophysical climate change mitigation potential of Canada's forest sector. Biogeosciences, 2014. 11: p. 3515-3529.

20. Murray, B.C., McCarl, B.A., and Lee, H.-C., Estimating Leakage from Forest Carbon Sequestration Programs. Land Economics, 2004. 80(1): p. 109-124.

21. Stinson, G. and Freedman, B., Potential for carbon sequestration in Canadian forests and agroecosystems. Mitigation and Adaptation Strategies for Global Change, 2001. 6(1): p. $1-23$. 
22. Stoehr, M., Woods, J., Bird, K., and Hayton, L., Verifying genetic gain estimates in coastal Douglas-fir in British Columbia. Ministry of Forests and Range Forest Science Program. Extension Note 104. 2011: p. 1-5.

23. Seely, B., Welham, C., and Kimmins, H., Carbon sequestration in a boreal forest ecosystem: results from the ecosystem simulation model, FORECAST. Forest Ecology and Management, 2002. 169(1-2): p. 123-135.

24. Lamers, P., Junginger, M., Dymond, C.C., and Faaij, A., Damaged forests provide an opportunity to mitigate climate change. GCB Bioenergy, 2013. 6(1): p. 44-60.

25. Carlson, M., Chen, J., Elgie, S., and Henschel, C., Maintaining the role of Canada's forests and peatlands in climate regulation. The Forestry Chronicle, 2010. 86(4): p. 434-443.

26. Wang, T., Campbell, E.M., O'Neill, G.A., and Aitken, S.N., Projecting future distributions of ecosystem climate niches: Uncertainties and management applications. Forest Ecology and Management, 2012. 279: p. 128-140.

27. Dymond, C.C., Forest carbon in North America: annual storage and emissions from British Columbia's harvest, 1965-2065. Carbon balance and management, 2012. 7(8): p. 1-10.

28. Lippke, B., Wilson, J., Meil, J., and Taylor, A., Characterizing the importance of carbon stored in wood products. Wood and Fiber Science, 2010. 42: p. 5-14.

29. Greig, M. and Bull, G., Carbon Management in British Columbia's Forests: Opportunities and Challenges. FORREX Series 24. 2008, Kamloops, Canada: Forum for Research and Extension in Natural Resources Society (FOREX).

30. Amichev, B.Y., Kurz, W.A., Smyth, C., and Rees, K.C.J., The carbon implications of largescale afforestation of agriculturally marginal land with short-rotation willow in Saskatchewan. GCB Bioenergy, 2011. 4(1): p. 70-87.

31. Dymond, C.C. and Kamp, A., Fibre use, net calorific value, and consumption of forestderived bioenergy in British Columbia, Canada. Biomass and Bioenergy, 2014. 70: p. 217224.

32. McKechnie, J., Colombo, S., Chen, J., Mabee, W., and MacLean, H.L., Forest bioenergy or forest carbon? Assessing trade-offs in greenhouse gas mitigation with wood-based fuels. Environmental Science \& Technology, 2011. 45(2): p. 789-795. 